\title{
Preliminary results of GOCE-based height system unification between Greece and Turkey over marine and land areas
}

\author{
Georgios S. Vergos ${ }^{1} \cdot$ Bihter Erol $^{2} \cdot$ Dimitrios A. Natsiopoulos ${ }^{1}$ • \\ Vassilios N. Grigoriadis ${ }^{1} \cdot$ Mustafa Serkan Işık $^{2}$ • \\ Ilias N. Tziavos ${ }^{1}$
}

Received: 1 February 2017/Accepted: 2 August 2017/Published online: 21 August 2017

(C) Akadémiai Kiadó 2017

\begin{abstract}
The unification of local vertical datums (LVDs) at a country-wide scale has gained significant attention lately due to the availability of GOCE-based global geopotential models (GGMs) and the unprecedented geoid height accuracies offered. Within a single country, several LVDs may be used, especially in the case of islandic nations. Therefore, the unification of all of them to a single nation-wide LVD is of utmost importance. The same holds for neighboring countries, where the unification of their vertical datums is necessary as a tool of engineering, cross-border collaboration and environmental and risk management projects. The aforementioned set the main scope of the present study, which focuses on the use of GOCE and GOCE/GRACE GGMs in order to investigate the offsets between the Greek and Turkish LVDs. First an evaluation of the latest release 5 GOCE GGMs is carried out, either to their maximum degree or through spectral enhancement with EGM208 and topographic effects. Then, the geopotential value for the Greek and Turkish LVDs is performed, along with different estimates for the marine area of the Aegean Sea where several islands and isles exist with each one realizing its own LVD. The relative offset between the two LVDs was determined and used to provide a direct link between the Greek and Turkish LVDs with the IAG conventional value recently proposed as a global WHS. From the results achieved it was concluded that the spectrally enhanced GOCE GGMs reduce the standard deviation of the differences with GPS/levelling data by $2-4 \mathrm{~cm}$ over Turkey and $2 \mathrm{~cm}$ for mainland Greece. In terms of the zero-level geopotential determination, the LVD of the Greek mainland is $64.9 \mathrm{~cm}$ below the IAG conventional value, while that of Turkey is $9.6 \mathrm{~cm}$ above. Finally, it is concluded that in practice each Greek island realizes its own LVD with offsets between them as large as $35 \mathrm{~cm}$. Despite that fact, the spectrally enhanced GOCE GGMs and in particular
\end{abstract}

Georgios S. Vergos

vergos@topo.auth.gr

1 Laboratory of Gravity Field Research and Applications - GravLab, Department of Geodesy and Surveying, Aristotle University of Thessaloniki, 54124 Thessaloníki, Greece

2 Department of Geomatics Engineering, Faculty of Civil Engineering, Istanbul Technical University, Istanbul, Turkey 
GOCO05s provides the overall smallest height residuals over the islands, hence the $\widehat{W}_{o}^{L V D}$ based on that can be recommended as the best estimate. In that way, relative offsets with the LVD of mainland Greece can be computed for each island, ranging between -23.8 and $15.5 \mathrm{~cm}$.

Keywords Local vertical datum - GOCE - Unification · Hellenic and Turkish datums · Vertical offsets

\section{Introduction}

The end of the GOCE mission in 2013 resulted in an abundance of gradiometric observations offering unprecedented high-accuracy information for the medium frequencies of the gravity field spectrum. Apart from the obvious improvements that GOCE offered to gravity field and geoid approximation (Andritsanos et al. 2015; Carrion et al. 2015; Gruber et al. 2011; Hirt et al. 2011; Šprlák et al. 2012; Vergos et al. 2014; Tziavos et al. 2016) and the contribution to mapping the dynamic ocean topography and ocean circulation (Albertella et al. 2012; Knudsen et al. 2011; Tziavos et al. 2013), an emerging issue is the unification of local vertical datums (LVDs) to a World Height System (WHS). Height System Unification (HSU) refers in essence to the determination of vertical offsets between the various vertical datums, either within the limits of a country, regional ones or on a world scale between countries and continents. These vertical offsets can be treated from either an oceanographic or a geodetic approach. The former refers to the utilization of mean sea level (MSL) data at tide-gauges (TGs) and their connection by a mean dynamic topography model, the latter estimated by purely oceanographic methods (Niiler et al. 2003), geodetic approaches (Bingham et al. 2011) or an assimilation of both (Rio and Hernandez 2004). The geodetic ones can be categorized in two classes, those employing the formulation of the Geodetic Boundary Value Problem (GBVP) through gravity anomaly data (Heck and Rummel 1990) and those utilizing available global geopotential models (GGMs) and GNSS/levelling observations on trigonometric benchmarks (Burša et al. 2001).

With GOCE focusing on improving the long-to-medium and medium wavelengths of the Earth's gravity field, recent GOCE and GOCE/GRACE based (GGMs) offer new opportunities for the unification of LVDs and heights at a country-wide scale. As a result, GOCE data are widely used for the determination of the zero-level geopotential value towards the unification of LVDs to a global one (Grigoriadis et al. 2014; Gruber et al. 2012; Kotsakis et al.2012; Vergos et al. 2015). The improvements in the entire spectral band lead to absolute geoid height accuracies for the latest Release5 GGMs at the $1.8 \mathrm{~cm}$ level to d/o 200-210 (Gruber and Rummel 2014).

This work focuses on the determination of the geopotential value for the Greek and Turkish LVDs, referring to both mainland areas and the Greek islands, employing GOCEbased GGMs and GNSS/levelling observations. This is carried out for each region separately performing different estimates using pure GOCE and GOCE/GRACE geopotential models, as well as spectrally enhanced information associated with the EGM2008 geopotential model (Pavlis et al. 2012). 


\section{Methodology and data used}

Before carrying out the determination of the zero-level geopotential for the areas of Greece and Turkey, a validation of geoid undulations derived from the GOCE/GRACE GGMs $\left(N^{G O C E}\right)$ has been performed against an external dataset of "geometric" geoid heights from collocated GPS and spirit levelling observations on trigonometric BMs $\left(N^{\text {GPS/Lev }}\right)$. The scope of this pre-processing steps was to provide an assessment of the latest GOCE/ GRACE GGMs for both Greece and Turkey and then determine the optimal degree and order (d/o) after which the satellite only GGMs will be spectrally enhanced with EGM2008.

\subsection{GOCE/GRACE GGM evaluation}

The GGMs evaluated refer to the latest release 5 (R5) models based on the time-wise (TIM), direct (DIR) and GOCE combined with GRACE (GOCO) models. Table 1 (Barthelmes and Köhler 2016) summarizes the models used along with their maximum d/o $\left(n_{\max }\right)$ of expansion and the data sources used for each one. The computation of GGM geoid undulations $\left(N^{G O C E}\right)$ has been carried out as outlined in Heiskanen and Moritz (1967, Eqs. 8.100-8.102), so that first height anomalies $\zeta$ have been estimated. The height anomaly has been computed from the spherical harmonic series expansions based on the spherical harmonic coefficients of each model and the Geodetic Reference System 1980 (GRS80) normal gravity field parameters. The conversion from height anomalies to geoid heights has been performed through the Bouguer anomaly within the harm_synth software (Pavlis et al. 2012) using the spherical harmonics expansion of the SRTM (Bamler 1999) model to represent Earth's topography. The contribution of the zero-degree geoid term $N_{o}$ to the GGM geoid undulations with respect to a specific reference ellipsoid, has been determined as:

$$
N_{o}=\frac{G M-G M_{o}}{R \gamma}-\frac{W_{o}-U_{o}}{\gamma},
$$

In all computations, the numerical values for the defining geocentric gravitational constant and the derived physical constant of the potential at the GRS80 ellipsoid (Moritz 2000)

Table 1 GOCE/GRACE GGMs used for the definition of the Greek and Turkish LVDs and their relative offset

\begin{tabular}{|c|c|c|c|}
\hline Models & Nmax & Data & Reference \\
\hline EGM2008 & 2190 & S(GRACE), G, A & $\begin{array}{l}\text { Pavlis et al. } \\
\text { (2012) }\end{array}$ \\
\hline GOCO05S & 280 & $\begin{array}{l}\text { GOCE, GRACE, Kinematic orbits ( } 8 \\
\text { satellites), SLR (6 satellites) }\end{array}$ & $\begin{array}{l}\text { Mayer-Gürr et al. } \\
\text { (2015) }\end{array}$ \\
\hline GO_CONS_GCF_2_TIM_R5 & 280 & $\mathrm{~S}(\mathrm{GOCE})$ & $\begin{array}{l}\text { Brockmann et al. } \\
\text { (2014) }\end{array}$ \\
\hline GO_CONS_GCF_2_DIR_R5 & 300 & S(Goce,Grace,Lageos) & $\begin{array}{l}\text { Bruinsma et al. } \\
\text { (2013) }\end{array}$ \\
\hline
\end{tabular}

Data: $S$ satellite tracking data, $G$ gravity data, $A$ altimetry data, GRACE Gravity Recovery and Climate Experiment, GOCE gravity field and steady state Ocean Circulation Explorer, LAGEOS Laser GEOdynamics Satellite, $S L R$ satellite laser ranking 
have been used as $G M_{o}=398600.5000109 \mathrm{~m}^{3} \mathrm{~s}^{-2}$ and $U_{o}=62636860.850 \mathrm{~m}^{2} \mathrm{~s}^{-2}$. The Earth's geocentric gravitational constant $G M$ and the gravity potential at the geoid $W_{o}$ are set to $G M=398600.4418109 \mathrm{~m}^{3} \mathrm{~s}^{-2}$ and $W_{o}=62636853.40 \mathrm{~m}^{2} \mathrm{~s}^{-2}$, as given by the IERS Conventions (Petit and Luzum 2010) and adopted by IAG during the last IUGG General Assembly in Prague 2015 (IAG Resolution No. 1; Sánchez et al. 2016), respectively. Mean Earth's radius $R$ has been taken equal to $R=6371008.7714 \mathrm{~m}$ and the normal gravity $\gamma$ at the surface of the ellipsoid has been computed for each benchmark (BM) by the closed formula of Somigliana (Heiskanen and Moritz 1967). All computations of the zero-degree term $N_{o}$ used in this study have been carried out in the conventional Tide Free (TF) system. Moreover, when a given GGM refers to the Zero Tide (ZT) system, the $C_{2,0}$ coefficient is converted to TF using the formula reported in Rapp et al. (1991, Eqs. 1-2). In all cases the evaluation of the GOCE and GOCE/GRACE GGMs was carried out by forming for each network point the differences relative to the GPS/Lev "geometric" geoid heights as:

$$
\Delta \mathrm{N}_{i}=N_{i}^{G P S / \text { Lev }}-N_{i}^{G O C E}=h_{i}-H_{i}^{\text {Helm }}-\left.N_{G O C E}\right|_{2} ^{n_{\max }}-\left.N_{R T M}\right|_{n_{\max }+1} ^{216,000}-N_{0},
$$

or, when using EGM2008 for the GOCE GGM spectral enhancement as:

$$
\Delta \mathrm{N}_{i}=h_{i}-H_{i}^{H e l m}-\left.N_{G O C E}\right|_{2} ^{n_{1}}-\left.N_{E G M 2008}\right|_{n_{1+1}} ^{2160}-\left.N_{R T M}\right|_{2161} ^{216,000}-N_{0} .
$$

In Eqs. (2) and (3) the residual terrain model (RTM) effects on the estimated geoid heights, $\left.N_{R T M}\right|_{n_{\max }+1} ^{216,000}$ and $\left.N_{R T M}\right|_{2161} ^{216,000}$, come from an SRTM-based 3 arcsec digital terrain model so that the geoid spectrum represented is equivalent to $d / o$ 216,000 and the geoid omission error can be neglected in both the GOCE/GRACE GGM evaluation and the subsequent zero level geopotential determination (Tziavos et al. 2010). RTM effects have been evaluated with the Gravsoft (Forsberg and Tscherning 2008) suite of programs, following the processing methodology outlined in Tziavos et al. (2010) for the generation of the reference DTM. Moreover, $n_{1}$ denotes the cut-off degree to which GOCE models are evaluated to, $h_{i}$ denotes the ellipsoidal height of the $\mathrm{BM}$ and $H_{i}^{\text {Helm }}$ is the Helmert orthometric height with respect to the LVD under consideration. Especially for Greece, where orthometric heights refer to the Mean Tide (MT) system, they have been converted to the tide-free (TF) system following Ekman (1989):

$$
H^{T F}-H^{M T}=0.68\left(0.099-0.269 \sin ^{2} \varphi\right) .
$$

\section{2 $\widehat{W}_{o}^{L V D}$ determination from GOCE/GRACE GGMs}

For the determination of the zero-level geopotential value $\widehat{W}_{o}^{L V D}$ for the Greek and Turkish LVDs the procedure presented in Grigoriadis et al. (2014) has been followed. The estimator for the local geopotential value of each LVD relies on the heterogeneous height data available for each set of trigonometric BMs and geoid heights from the GOCE/GRACE GGMs either pure or spectrally enhanced ones with EGM2008. Therefore, $\widehat{W}_{o}^{L V D}$ can be estimated as:

$$
\widehat{W}_{o}^{L V D}=W_{o}^{C V D}-\frac{\sum_{i=1}^{m} \Delta C_{i}}{m},
$$

where $W_{o}^{C V D}$ represents a conventional zero-level geopotential for the world height system (WHS), $\widehat{W}_{o}^{L V D}$ represents the estimated zero-level geopotential of the LVD, $\Delta C_{i}$ is the 
geopotential number of the network BM under consideration, relative to the WHS zerolevel geopotential, and $m$ is the number of BMs. In the present study, the IAG adopted best estimate for the zero-level geopotential determined by Sánchez et al. (2016) has been used, so that $W_{o}^{C V D}=62636853.4 \mathrm{~m}^{2} / \mathrm{s}^{2}$. The geopotential numbers in Eq. (5) can be derived from the triplet of heights available for the BMs in each area, as:

$$
\Delta C_{i}^{C V D / L V D}=\Delta N_{i} \bar{g}_{i},
$$

with $\Delta \mathrm{N}_{i}$ being outlined in Eqs. (2) and (3) and $g_{i}$ denoting the mean value of gravity for each station. The evaluation of the mean gravity is based on the Poincare-Prey reduction scheme (Heiskanen and Moritz 1967). Given that no actual gravity observations $g_{i}$ have been used in the present study, they have been synthesized from the normal gravity and the radial derivative of the disturbing potential following Filmer et al. (2010).

\subsection{Local data availability}

Over Turkey, the GOCE and GOCE/GRACE GGMs are evaluated using regionally and locally distributed GPS/levelling BMs having ellipsoidal heights in ITRF96 and orthometric heights in the Turkish National Vertical Control Network (TUDKA-99) datum, respectively. The vertical datum in Turkey (Turkey National Vertical Control Network Datum-TUDKA) is based on the average of sea level observations at the Antalya tidegauge (TG) station between 1936 and 1971 ( $~ 35$ years). TUDKA is a classic vertical datum in the sense that it relies and is tied to the MSL (Ayhan and Demir 1993; Ayhan et al. 2002) instead of the geoid. For both the evaluation of the GOCE and GOCE/GRACE GGMs and the subsequent determination of the zero-level geopotential over Turkey, three sets of GPS/levelling on BMs data have been available. These constitute of $30 \mathrm{BMs}$ covering the entire country over network stations of the Turkish National Fundamental GPS Network (TUTGA). Their orthometric heights refer to the TUDKA-99 datum through conventional leveling measurements (see Fig. 1 top). Moreover, 81 densely sampled GPS/ levelling BMs (1 benchmark per $40 \mathrm{~km}$ ) are available over the Marmara region, northwest Turkey (see Fig. 1 bottom left). Finally, 309 GPS/levelling BMs are available in the area of Izmir (see Fig. 1 bottom eight), which belong to a third order densification network and have an average density of 1 point per $8 \mathrm{~km}$ (Ayan et al. 2001).

The Greek data available for this study consist of BMs in both mainland (1542 BMs) and the Greek islands (797 BMs), being part of the national trigonometric and leveling networks (see Fig. 2). The Greek GPS/levelling on BMs dataset is based on orthometric heights from the Hellenic Military Geographic Service (HMGS) measured during the reestablishment of the Hellenic Vertical Datum in 1985 (HVD85) (Takos 1989). HVD85 models the physical heights as Helmert orthometric heights. For the mainland BMs, their tie is formally to the TG station at Piraeus harbor, so that the HVD85 origin is relative to a MSL determined with sea level measurements for the period 1933-1978. Today, the true accuracy of the HVD is unknown, since (a) it was not uniformly adjusted, (b) it is not maintained by HMGS, and (c) the formal errors provided by HMGS are ambiguous and over optimistic (Kotsakis and Katsambalos 2010; Tziavos et al. 2012; Vergos et al. 2014). 


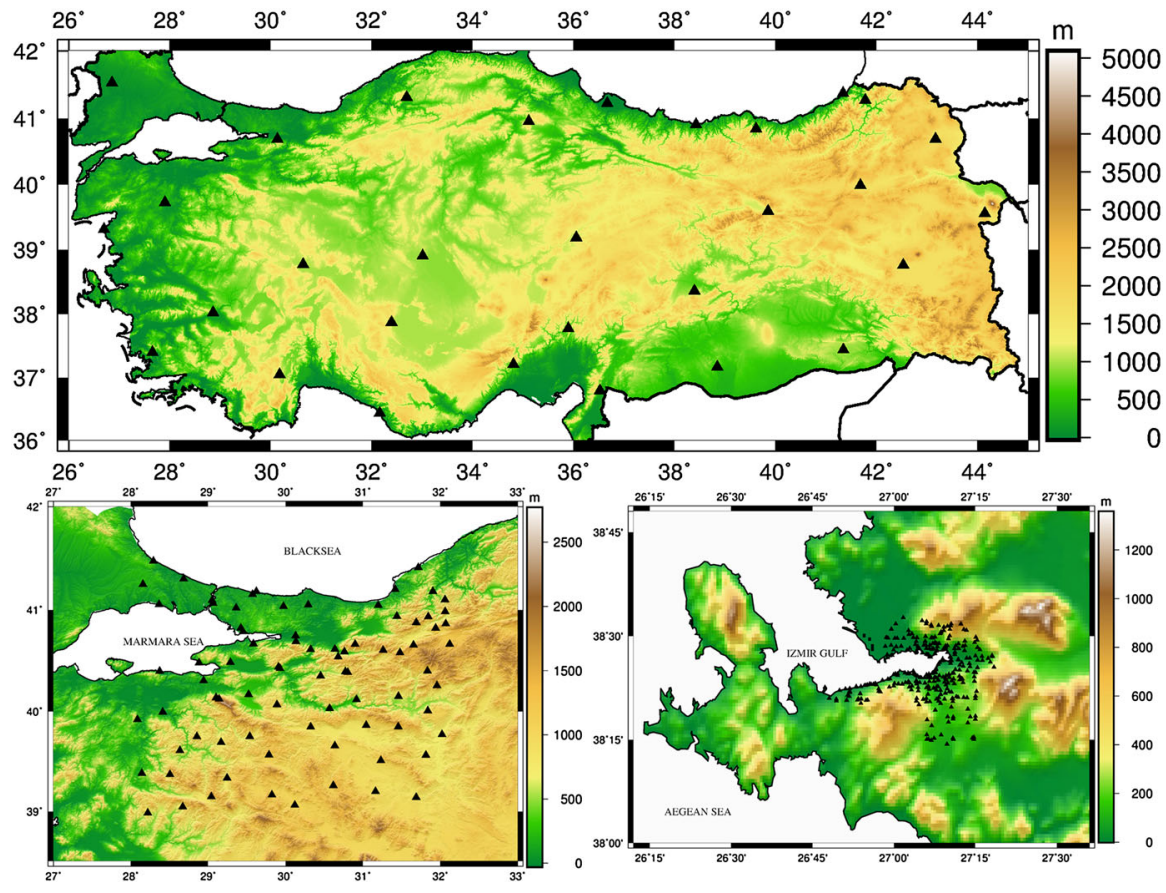

Fig. 1 GPS/leveling data availability in Turkey. 30 TUTGA BMs (top), 81 TUTGA BMs in the Marmara region of NW Turkey (bottom-right) and 301 IzJRS densification network BMs in the central-west of Turkey (bottom-right)

Fig. 2 The available GPS/ levelling BMs over Greece. 1542 BMs in mainland and 797 over the islands

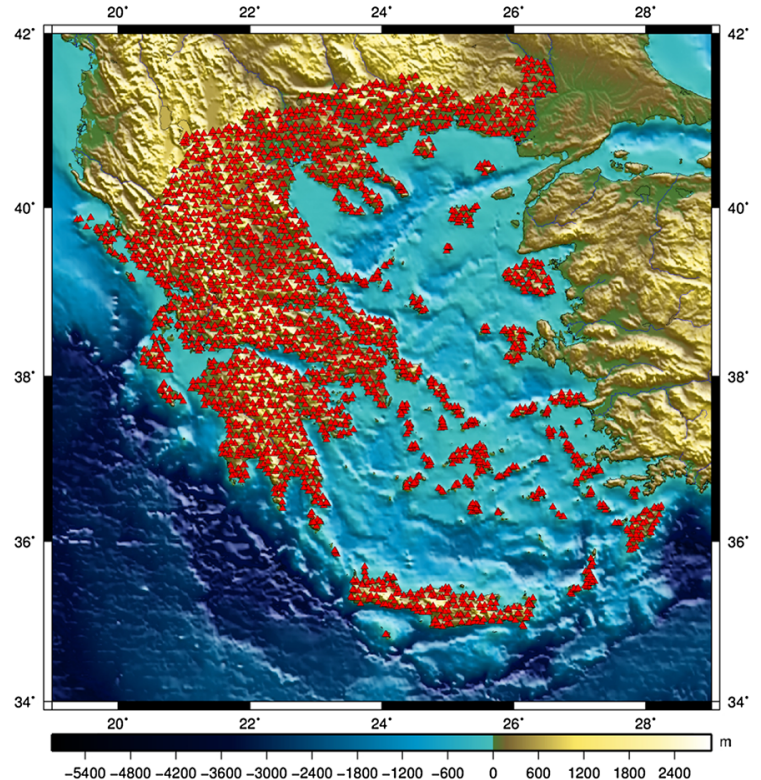

$-5400-4800-4200-3600-3000-2400-1800-1200-600 \quad 0 \quad 600 \quad 1200 \quad 1800 \quad 2400$ 


\section{Evaluation of GOCE/GRACE GGMs with in situ GNSS and orthometric height data}

As already mentioned, for both test areas the latest GO-DIR-R5, GO-TIM-R5 and GOCO05s GGMs, either alone or through their spectral enhancement with EGM2008 and the RTM contribution have been evaluated (Table 1). The validation was carried out per degree for all GGMs over the Greek mainland and per 5 degree steps for the areas of Marmara and Izmir in Turkey. Figure 3 displays the standard deviation (std) of the differences between the "geometric" geoid heights and the GOCE/GRACE GGMs over Turkey, Marmara and İzmir regions per varying $\mathrm{d} / \mathrm{o}$, while the statistics are reported in Table 2. Considering the varying std of geoid height residuals when spectral enhancement is used, the optimal degrees for the models are found at d/o 235, 155 and 245, respectively, for the 30 and 81 TUTGA BMs and those in İzmir region. However, it is noticed that for all three BM datasets, d/o 245 provides a homogeneously small std. Therefore, although varying optimum degrees are considered in this study, d/o 245 may be recommended as a Turkey-wide optimal cut-off degree for the use of GOCE/GRACE based GGMs in GNSS/ levelling evaluation studies. In the sequel, $\widehat{W}_{o}^{L V D}$ for Turkey will be based on d/o 155 for the 81 TUTGA BMs, d/o 245 for the 30 TUTGA and d/o 245 for the 301 Izmir BMs.

The assessment results for the Greek mainland are depicted in Fig. 4, where the std of the EGM2008 and RTM enhanced geoid height residuals depending on varying d/o are presented, while the statistics are reported in Table 2. For Greece it can be concluded that the optimal combination degree for the spectral enhancement with EGM2008 is 170-172, where all GOCE/GRACE models consistently provide their overall smaller std, being about $2 \mathrm{~cm}$ better than that of EGM2008, which is at the $14.1 \mathrm{~cm}$ level. The GOCE models perform almost equally well, with DIR-R5 deviating from TIM-R5 and GOCO05 in the spectral range between d/o 138-184, being worst by $0.2-0.5 \mathrm{~cm}$. After d/o 245, DIR-R5 is better by few mm up to $1.6 \mathrm{~cm}$ compared to TIM-R5 and GOCO05s, showing that it probably retains the geoid signal power better up to a higher degree of expansion. Nevertheless, and in order to unify the calculations for all GGMs, a d/o 170 has been selected for Greece as the optimum one.

\section{Determination of the zero-level geopotential $\widehat{W}_{o}^{L V D}$ for Greece and Turkey}

For both countries, two estimations have been carried out either employing the maximum d/o of the GOCE/GRACE models and the optimal combination degree for the spectral enhancement with EGM2008. It should be noted that the results for the Greek mainland on the estimation of the $\widehat{W}_{o}^{L V D}$ are not reported here in detail, since they have been presented in Grigoriadis et al. (2014) and Vergos et al. (2015). For the sake of completeness the derived values for the Greek mainland LVD are repeated since they form the reference for the comparison with the islands. Given the residuals presented for the Greek mainland (see Table 2), GOCO05s spectrally enhanced with EGM2008 has been used in the determination of the zero-level geopotential for the continental part of Greece. This has been estimated as $\widehat{W}_{o G R}^{L V D}=62636859.8902 \pm 0.015 \mathrm{~m}^{2} / \mathrm{s}^{2}$, i.e., the Greek is $64.90 \mathrm{~cm}$ below the conventional value adopted by Sánchez et al. (2016). Finally, given that geopotential values for the LVDs of 83 Greek islands have been determined, hence the respective 
Fig. 3 GGMs validation at 30 TUTGA BMs (top) 81 TUTGA BMs (middle) and 301 IzJRS BM (bottom). Standard deviation of the geoid undulation residuals $\left(N^{G P S}-N_{\text {comb }}^{G G M}\right)$ with varying $\mathrm{d} / \mathrm{o}$ of expansion and EGM08 enhancement
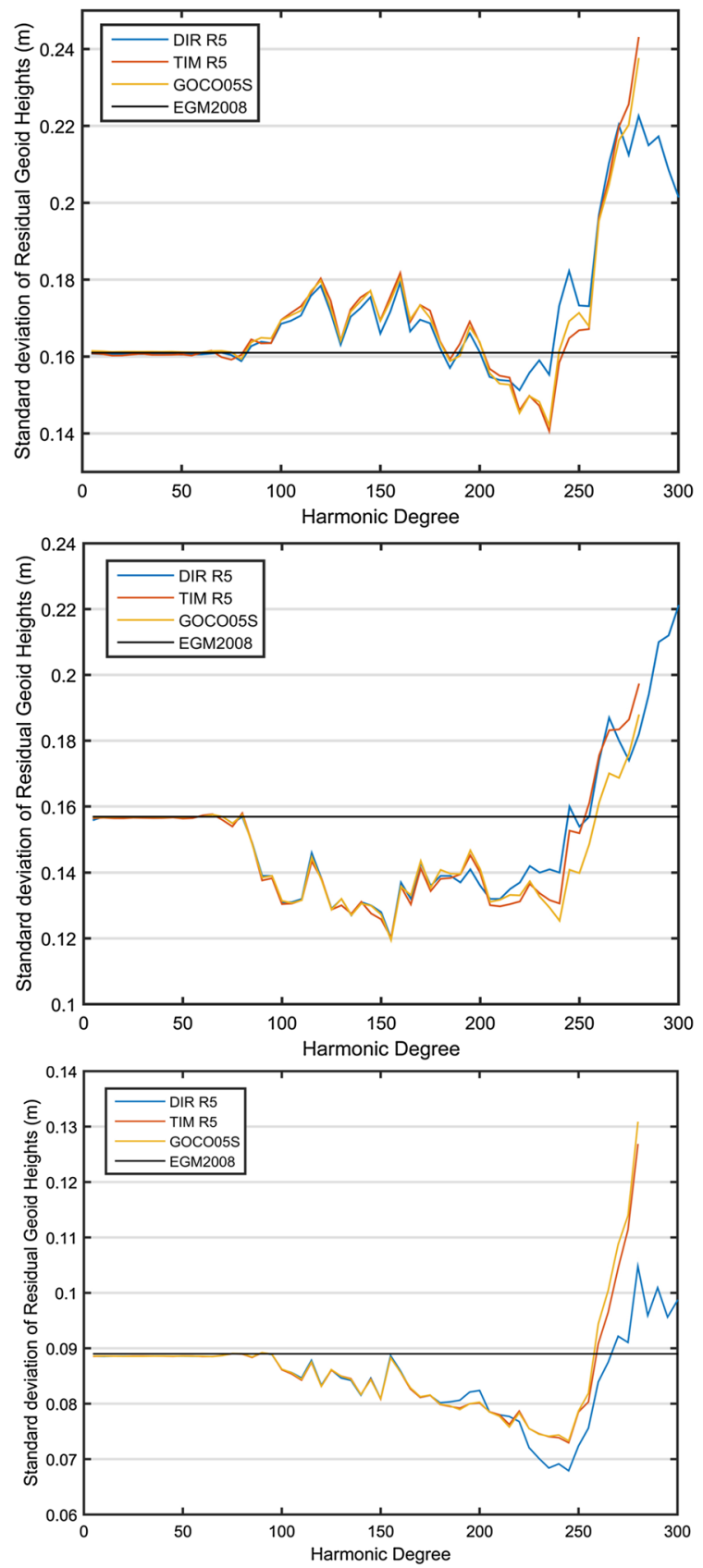

tables are quite large, explicit estimates are given only for eleven (11) of them, being the largest ones in the Hellenic territory The results for the rest of the islands are provided as an electronic supplementary material in the permanent link http://vergos.webpages.auth.gr/ images/Publications/AGetG_Wo_2017.Appendix.pdf. The 11 islands for which the results 
Table 2 Standard deviations of geoid height residuals, for the worst, optimum and maximum degrees of the GGMs for mainland Greece, the Turkey-wide, Marmara and İzmir regions [unit: (m)]

\begin{tabular}{lllllll}
\hline GGM & Worst d/o & Std & Best d/o & Std & Max d/o & Std \\
\hline Mainland Greece & & & & & \\
TIM-R5 & 280 & 0.226 & 166 & 0.122 & 280 & 0.226 \\
DIR-R5 & 298 & 0.261 & 169 & 0.124 & 300 & 0.259 \\
GOCO05s & 280 & 0.226 & 166 & 0.121 & 280 & 0.226 \\
TUTGA 30-Turkey wide & & & & & \\
TIM-R5 & 280 & 0.241 & 235 & 0.141 & 280 & 0.241 \\
DIR-R5 & 300 & 0.201 & 220 & 0.151 & 300 & 0.201 \\
GOCO05s & 280 & 0.239 & 235 & 0.142 & 280 & 0.239 \\
TUTGA 81-Marmara & & & & & \\
TIM-R5 & 280 & 0.197 & 155 & 0.120 & 280 & 0.197 \\
DIR-R5 & 300 & 0.221 & 155 & 0.120 & 300 & 0.221 \\
GOCO05s & 280 & 0.188 & 155 & 0.120 & 280 & 0.180 \\
Izmir & & & & & & \\
TIM-R5 & 280 & 0.127 & 245 & 0.073 & 280 & 0.127 \\
DIR-R5 & 280 & 0.105 & 245 & 0.068 & 300 & 0.099 \\
GOCO05s & 280 & 0.131 & 245 & 0.073 & 280 & 0.131 \\
\hline
\end{tabular}

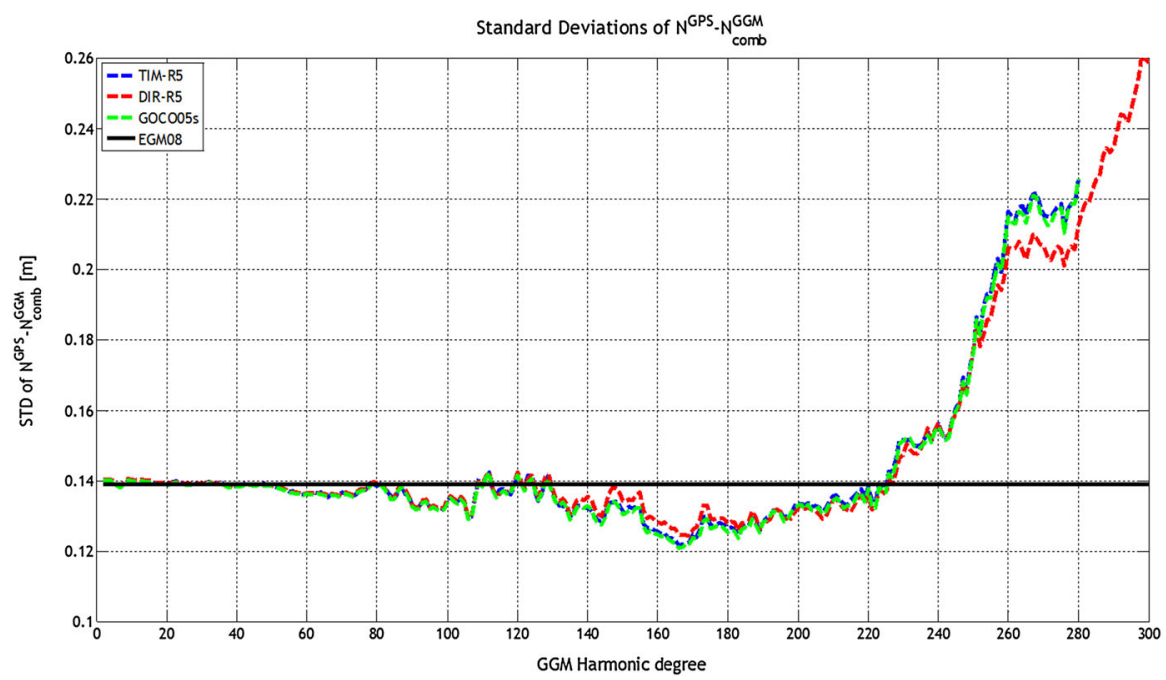

Fig. 4 Validation of the TIM-R5, DIR-R5 and GOCO05s GGMs over mainland Greece. Standard deviation of the geoid undulation residuals $\left(N^{G P S}-N_{c o m b}^{G G M}\right)$ with varying d/o of expansion and EGM08 enhancement

are presented analytically are depicted in Fig. 5, being: Crete (1) and Rhodes (2) in the southern part of Aegean Sea; Samos (3), Chios (4), Eyvoia (8) in the central Aegean; Lesvos (5), Limnos (6), Thasos (7) in the northern part; and Zakynthos (9), Kefalonia (10) and Corfu (11) in the Ionia Sea. The number in the bracket after each island corresponds to the position of the island as depicted in Fig. 5. 
Fig. 5 Location of the main Greek islands for which the analytic derivation of $\widehat{W}_{o}^{L V D}$ is presented

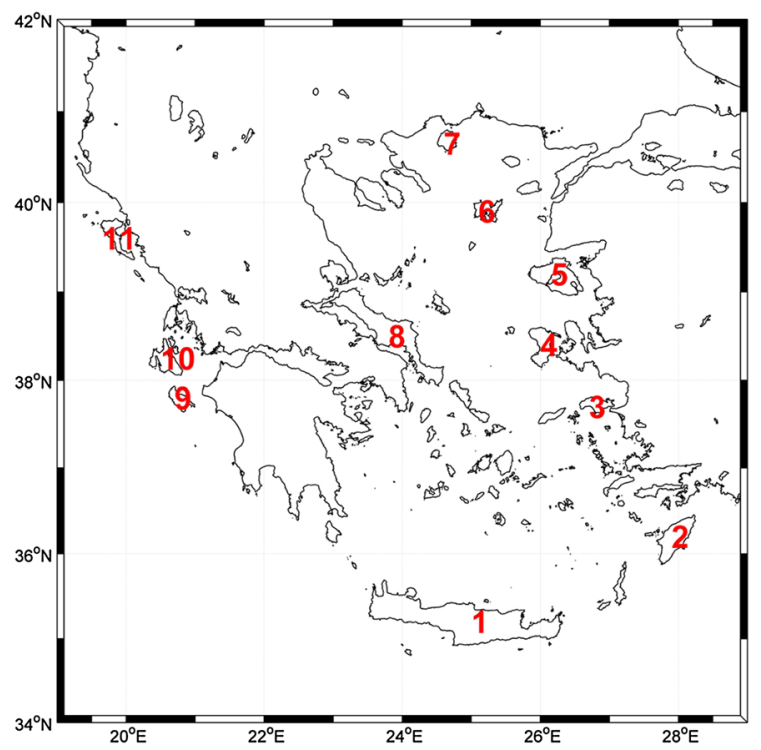

\section{1 $\widehat{W}_{o}^{L V D}$ determination over the Greek islands}

First, the maximum d/o of the spherical harmonics expansion of the DIR-R5, TIM-R5 and GOCO05s models are employed for the Greek islands. Greece as an islandic nation has many vertical datum realizations, and as a result each Greek island has its own vertical datum definition. Tables 3 and 4 present both the results of the EGM2008 and GOCEbased evaluation at the GPS/levelling BMs over the Greek islands as well as the zero-level

Table 3 Height residuals and $\widehat{W}_{o}^{L V D}$ for the Greek islands based on EGM2008 to d/o 2190 [unit: (cm)]

\begin{tabular}{|c|c|c|c|c|c|c|c|}
\hline \multirow{2}{*}{$\begin{array}{l}\text { Study area (Greek } \\
\text { Islands) } \\
\text { EGM08 (d/o 2190) }\end{array}$} & \multicolumn{5}{|c|}{$\begin{array}{l}\text { Geoid height residuals } \\
\left(N_{G P S / l e v .}-N_{\text {model }}\right)\end{array}$} & \multicolumn{2}{|c|}{$\begin{array}{l}\text { Gravity potential and offsets relative to } \\
W_{o}=\ldots .53 .4000 \mathrm{~m}^{2} / \mathrm{s}^{2}\end{array}$} \\
\hline & Min & Max & Mean & Std & Rms & $\widehat{W}_{o}^{L V D}\left(\mathrm{~m}^{2} / \mathrm{s}^{2}\right)$ & $\begin{array}{l}\approx \delta \widehat{W}_{o}^{L V D} \\
(\mathrm{~cm})\end{array}$ \\
\hline CRETE & -125.2 & -31.7 & -82.1 & 18.0 & 84.0 & $62,636,860.7702 \pm 0.0705$ & -73.7 \\
\hline RHODES & -125.2 & -18.5 & -31.8 & 14.7 & 35.1 & $62,636,856.2443 \pm 0.1511$ & -28.4 \\
\hline SAMOS & -174.3 & -62.6 & -82.7 & 27.9 & 87.0 & $62,636,862.4542 \pm 0.2355$ & -90.5 \\
\hline CHIOS & -69.1 & -21.7 & -39.9 & 12.7 & 41.8 & $62,636,858.8076 \pm 0.1799$ & -54.1 \\
\hline LESVOS & -90.1 & -54.2 & -75.0 & 9.1 & 75.5 & $62,636,861.7996 \pm 0.1411$ & -84.0 \\
\hline LIMNOS & -90.9 & -51.7 & -75.4 & 9.1 & 75.9 & $62,636,860.6447 \pm 0.2078$ & -72.4 \\
\hline THASOS & -67.3 & -47.6 & -56.4 & 6.2 & 56.7 & $62,636,859.6481 \pm 0.3117$ & -62.5 \\
\hline EYVOIA & -103.3 & -37.4 & -69.6 & 11.7 & 70.5 & $62,636,859.4835 \pm 0.0979$ & -60.8 \\
\hline ZAKYNTHOS & -90 & -66.9 & -76.2 & 5.8 & 76.4 & $62,636,860.8914 \pm 0.2544$ & -74.9 \\
\hline KEFALONIA & -82.2 & -40.8 & -63.0 & 9.7 & 63.7 & $62,636,859.7018 \pm 0.1971$ & -63.0 \\
\hline CORFU & -101.5 & -45.2 & -84.2 & 16.8 & 85.8 & $62,636,862.0126 \pm 0.2138$ & -86.1 \\
\hline
\end{tabular}


Table 4 Height residuals and $\widehat{W}_{o}^{L V D}$ for the Greek islands based on DIR-R5, TIM-R5 and GOCO05s to their $n_{\max }$ [unit: $\left.(\mathrm{cm})\right]$

\begin{tabular}{|c|c|c|c|c|c|c|c|}
\hline \multirow[t]{2}{*}{$\begin{array}{l}\text { Study area (Greek } \\
\text { Islands) }\end{array}$} & \multicolumn{5}{|c|}{$\begin{array}{l}\text { Geoid height residuals } \\
\left(N_{\text {GPS/lev. }}-N_{\text {model }}\right)\end{array}$} & \multicolumn{2}{|c|}{$\begin{array}{l}\text { Gravity potential and offsets relative to } \\
W_{o}=\ldots .53 .4000 \mathrm{~m}^{2} / \mathrm{s}^{2}\end{array}$} \\
\hline & Min & Max & Mean & Std & Rms & $\widehat{W}_{o}^{L V D}\left(\mathrm{~m}^{2} / \mathrm{s}^{2}\right)$ & $\begin{array}{l}\approx \delta \widehat{W}_{o}^{L V D} \\
(\mathrm{~cm})\end{array}$ \\
\hline \multicolumn{8}{|l|}{$D I R-R 5$ (d/o 300) } \\
\hline CRETE & -116.0 & 85.6 & -24.6 & 38.6 & 45.6 & $62,636,857.7708 \pm 0.0455$ & -43.7 \\
\hline RHODES & -116.0 & 136.8 & 1.6 & 65.7 & 65.4 & $62,636,846.6183 \pm 0.0975$ & 67.8 \\
\hline SAMOS & -158.6 & -4.9 & -30.9 & 38.4 & 48.2 & $62,636,855.4681 \pm 0.1520$ & -20.7 \\
\hline CHIOS & -68.0 & -11.5 & -32.9 & 14.4 & 35.8 & $62,636,856.9432 \pm 0.1161$ & -35.4 \\
\hline LESVOS & -89.0 & -8.0 & -51.4 & 17.1 & 54.1 & $62,636,858.7441 \pm 0.0911$ & -53.4 \\
\hline LIMNOS & -34.8 & -13.1 & -26.2 & 7.4 & 27.2 & $62,636,855.9545 \pm 0.1341$ & -25.5 \\
\hline THASOS & -57.8 & -20.2 & -35.9 & 15.4 & 38.7 & $62,636,858.3027 \pm 0.2012$ & -49.0 \\
\hline EYVOIA & -113.6 & 8.6 & -54.0 & 25.2 & 59.5 & $62,636,858.9612 \pm 0.0632$ & -55.6 \\
\hline ZAKYNTHOS & -61.9 & 76.2 & 36.1 & 43.8 & 55.4 & $62,636,852.8923 \pm 0.1642$ & 5.1 \\
\hline KEFALONIA & -2.3 & 120.4 & 75.1 & 37.5 & 83.5 & $62,636,844.1876 \pm 0.1272$ & 92.1 \\
\hline CORFU & -47.0 & 13.8 & -26.7 & 18.2 & 32.0 & $62,636,855.7217 \pm 0.1380$ & -23.2 \\
\hline \multicolumn{8}{|l|}{ TIM-R5 (d/o 280) } \\
\hline CRETE & -110.7 & 92.7 & -23.0 & 39.3 & 45.4 & $62,636,857.9335 \pm 0.1002$ & -45.3 \\
\hline RHODES & -110.7 & 130.6 & 2.4 & 63.5 & 63.3 & $62,636,846.8355 \pm 0.2147$ & 65.6 \\
\hline SAMOS & -172.0 & -24.2 & -49.1 & 37.0 & 60.7 & $62,636,857.3512 \pm 0.3347$ & -39.5 \\
\hline CHIOS & -67.4 & -4.7 & -30.6 & 15.6 & 34.2 & $62,636,856.6575 \pm 0.2556$ & -32.6 \\
\hline LESVOS & -87.3 & -3.3 & -50.2 & 18.9 & 53.5 & $62,636,858.6272 \pm 0.2005$ & -52.3 \\
\hline LIMNOS & -43.3 & -18.8 & -31.8 & 7.7 & 32.7 & $62,636,856.6178 \pm 0.2952$ & -32.2 \\
\hline THASOS & -58.7 & -16.5 & -31.0 & 15.4 & 34.2 & $62,636,857.7808 \pm 0.4429$ & -43.8 \\
\hline EYVOIA & -107.0 & 20.7 & -49.9 & 27.7 & 57.0 & $62,636,859.0956 \pm 0.1391$ & -57.0 \\
\hline ZAKYNTHOS & -50.9 & 86.9 & 47.0 & 43.5 & 62.8 & $62,636,851.7638 \pm 0.3615$ & 16.4 \\
\hline KEFALONIA & -10.9 & 120.0 & 74.3 & 38.9 & 83.4 & $62,636,844.2885 \pm 0.2800$ & 91.1 \\
\hline CORFU & -56.1 & 10.1 & -36.1 & 20.5 & 41.2 & $62,636,856.5538 \pm 0.3038$ & -31.5 \\
\hline \multicolumn{8}{|l|}{ GOCOO5S (d/o 280) } \\
\hline CRETE & -112.2 & 89.4 & -25.8 & 39.1 & 46.7 & $62,636,858.2652 \pm 0.1041$ & -48.7 \\
\hline RHODES & -112.2 & 133.4 & 1.1 & 64.9 & 64.7 & $62,636,846.7428 \pm 0.2230$ & 66.6 \\
\hline SAMOS & -169.5 & -21.4 & -46.1 & 37.2 & 58.5 & $62,636,857.0291 \pm 0.3475$ & -36.3 \\
\hline CHIOS & -69.5 & -7.1 & -33.2 & 15.4 & 36.4 & $62,636,856.9758 \pm 0.2654$ & -35.8 \\
\hline LESVOS & -83.6 & 0.5 & -46.6 & 19.0 & 50.2 & $62,636,858.2633 \pm 0.2082$ & -48.6 \\
\hline LIMNOS & -44.7 & -20.3 & -33.4 & 7.7 & 34.2 & $62,636,856.7740 \pm 0.3065$ & -33.7 \\
\hline THASOS & -56.8 & -14.5 & -29.0 & 15.5 & 32.4 & $62,636,857.5789 \pm 0.4598$ & -41.8 \\
\hline EYVOIA & -107.2 & 21.7 & -49.4 & 28.0 & 56.7 & $62,636,859.0565 \pm 0.1445$ & -56.6 \\
\hline ZAKYNTHOS & -51.6 & 85.2 & 45.6 & 43.2 & 61.5 & $62,636,851.8779 \pm 0.3753$ & 15.2 \\
\hline KEFALONIA & -9.0 & 120.7 & 75.0 & 38.7 & 84.0 & $62,636,844.2050 \pm 0.2908$ & 91.9 \\
\hline CORFU & -53.4 & 9.7 & -34.3 & 19.4 & 39.1 & $62,636,856.4032 \pm 0.3154$ & -30.0 \\
\hline
\end{tabular}


geopotential for each of the LVDs realized through the available BMs. It can be concluded that the best accuracies in terms of the std of the height residuals are achieved when EGM2008 is used for the majority of the islands. One point that should be stressed once more is that this evaluation has been carried out only for islands where a substantial number of BMs is available. Given their small size, it was assumed that if four or more BMs are available for any given island, then a good indication of both the GGM performance and the zero-level geopotential evaluation could be deduced. Considering the performance of EGM2008 over mainland Greece, giving a std of $14.0 \mathrm{~cm}$, it can be concluded that EGM2008 gives smaller residuals for seven of the major Greek islands. Interestingly, three of them reside in the NE Aegean Sea, i.e., Lesvos, Limnos and Thasos (see also Fig. 5) and are very close to each other, while the other two are Zakynhtos and Kefalonia, in the South Ionian Sea. Therefore, one could possibly assume that the LVDs realized in the triplet of the islands in the NE Aegean are somehow linked to each other, while the same could hold for the two islands in the South Ionian Sea.

The GOCE GGMs provide larger differences compared to EGM2008 in all cases, when used to their maximum d/o with the exception of Limnos. These larger differences compared to EGM2008 and hence the provided std can be interpreted as an evaluation of the GOCE omission error, for the DIR-R5, TIM-R5, and GOCO05S GGMs, over each of the islands. Over Limnos, all GOCE GGMs have consistently smaller std compared to EGM2008 at the 7.4-7.7 cm level compared to $9.1 \mathrm{~cm}$ for EGM2008. Moreover, the mean offset determined for Limnos is substantially different, being at the -25.5 to $-33.7 \mathrm{~cm}$ compared to IAG $W_{o}$, while EGM2008 gives an offset of $-72.4 \mathrm{~cm}$. A further point that should be considered is that even to their maximum $\mathrm{d} / \mathrm{o}$ the GOCE GGMs still have a significant geoid omission error. A global estimate of the remaining omission error for $\mathrm{d} / \mathrm{o}$ 300 is $\sim 23 \mathrm{~cm}$, either following Kaula's (1966) power law and the Tscherning and Rapp (1974) degree variance model. The large differences between the estimated $\widehat{W}_{o}^{L V D}$ values of each island can be attributed to the number of BMs available in each one, since a larger number of points translates usually, and if blunders are not present, to smaller prediction errors.

The next step in the evaluation and zero-level geopotential estimation referred to the spectral enhancement of GOCE GGMs with EGM2008. This has been carried out as outlined in Eq. (3), so by enhancing GOCE-derived geoid with EGM2008 after d/o 170. Table 5 summarizes both the residual geoid heights and the zero-level geopotential estimated for each of the main Greek islands. In all cases, the spectrally enhanced GOCE geoid heights provide equivalent or slightly better residuals compared to EGM2008, as far as both the std and the range are concerned. Figure 6 depicts the spatial distribution of the $\widehat{W}_{o}^{L V D}$ estimated for each of the LVDs over the Greek islands using the spectrally enhanced DIR-R5 and GOCO05s. From this figure and the statistics it can be seen that there is a general trend towards higher potential values, hence smaller differences with the conventional IAG $W_{o}$, from west to east and from north to south, with the difference between the two ends of the Hellenic territory being about $30-40 \mathrm{~cm}$. An exception to that pattern is viewed for Kastelorizo (see the electronic supplementary material), being the eastern-most of the Greek islands (south of Antalya Turkey) whose LVD is $\sim 83 \mathrm{~cm}$ above the conventional IAG $W_{o}$ for the WHS. From Table 5 it can be concluded as well that the spectrally enhanced GOCE GGM $\widehat{W}_{o}^{L V D}$ for the Greek islands agree to each other at the $0.1-0.5 \mathrm{~cm}$ level, showing very good robustness. For most of the islands the results provided by the enhanced GOCE models are superior to those of EGM2008 in terms of the std of the residuals. Despite the fact that the Greek mainland LVD is $64.90 \mathrm{~cm}$ lower 
Table 5 Height residuals and $\widehat{W}_{o}^{L V D}$ for the Greek islands based on the spectrally enhanced DIR-R5, TIMR5 and GOCO05s [unit: $(\mathrm{cm})$ ]

\begin{tabular}{|c|c|c|c|c|c|c|c|}
\hline \multirow[t]{2}{*}{$\begin{array}{l}\text { Study area (Greek } \\
\text { Islands) }\end{array}$} & \multicolumn{5}{|c|}{$\begin{array}{l}\text { Geoid height residuals } \\
\left(N_{\text {GPS/lev. }}-N_{\text {model }}\right)\end{array}$} & \multicolumn{2}{|c|}{$\begin{array}{l}\text { Gravity potential and offsets relative to } \\
W_{o}=\ldots .53 .4000 \mathrm{~m}^{2} / \mathrm{s}^{2}\end{array}$} \\
\hline & Min & Max & Mean & Std & Rms & $\widehat{W}_{o}^{L V D}\left(\mathrm{~m}^{2} / \mathrm{s}^{2}\right)$ & $\begin{array}{l}\approx \delta \widehat{W}_{o}^{L V D} \\
(\mathrm{~cm})\end{array}$ \\
\hline \multicolumn{8}{|l|}{$\operatorname{DIR}-R 5\left(\mathrm{~d} / \mathrm{o} 170^{+}\right)$} \\
\hline CRETE & -126.3 & -29.5 & -81.1 & 18.6 & 83.2 & $62,636,861.0799 \pm 0.0309$ & -76.8 \\
\hline RHODES & -126.3 & -19.0 & -43.9 & 14.3 & 46.2 & $62,636,857.4729 \pm 0.0663$ & -40.7 \\
\hline SAMOS & -175.3 & -63.6 & -84.1 & 27.8 & 88.3 & $62,636,861.5854 \pm 0.1033$ & -81.9 \\
\hline CHIOS & -69.4 & -21.6 & -40.0 & 12.8 & 41.9 & $62,636,857.9984 \pm 0.0789$ & -46.0 \\
\hline LESVOS & -89.6 & -53.3 & -74.4 & 9.1 & 74.9 & $62,636,861.0052 \pm 0.0619$ & -76.1 \\
\hline LIMNOS & -91.0 & -51.4 & -75.6 & 9.2 & 76.1 & $62,636,860.9385 \pm 0.0911$ & -75.4 \\
\hline THASOS & -68.3 & -48.3 & -57.3 & 6.2 & 57.6 & $62,636,859.1000 \pm 0.0871$ & -57.0 \\
\hline EYVOIA & -105.4 & -39.6 & -71.4 & 11.5 & 72.3 & $62,636,859.9132 \pm 0.0429$ & -65.1 \\
\hline ZAKYNTHOS & -90.8 & -67.3 & -77.0 & 5.9 & 77.2 & $62,636,860.9146 \pm 0.1115$ & -75.1 \\
\hline KEFALONIA & -83.6 & -42.6 & -64.7 & 9.6 & 65.4 & $62,636,859.3379 \pm 0.0864$ & -59.4 \\
\hline CORFU & -102.3 & -46.2 & -85.2 & 16.7 & 86.8 & $62,636,861.3689 \pm 0.0937$ & -79.7 \\
\hline \multicolumn{8}{|l|}{$T I M-R 5\left(d / o 170^{+}\right)$} \\
\hline CRETE & -124.8 & -31.0 & -81.4 & 18.0 & 83.4 & $62,636,861.1832 \pm 0.0322$ & -77.8 \\
\hline RHODES & -124.8 & -19.0 & -44.6 & 14.5 & 46.9 & $62,636,857.5704 \pm 0.0690$ & -41.7 \\
\hline SAMOS & -174.3 & -62.5 & -82.7 & 27.9 & 87.0 & $62,636,861.4349 \pm 0.1075$ & -80.3 \\
\hline CHIOS & -70.0 & -22.6 & -40.7 & 12.7 & 42.5 & $62,636,858.0401 \pm 0.0821$ & -46.4 \\
\hline LESVOS & -90.7 & -54.8 & -75.6 & 9.1 & 76.1 & $62,636,861.1291 \pm 0.0644$ & -77.3 \\
\hline LIMNOS & -91.4 & -52.1 & -76.0 & 9.2 & 76.5 & $62,636,860.9887 \pm 0.0948$ & -75.9 \\
\hline THASOS & -68.4 & -48.6 & -57.5 & 6.2 & 57.8 & $62,636,859.1287 \pm 0.1422$ & -57.3 \\
\hline EYVOIA & -104.2 & -38.6 & -70.6 & 11.6 & 71.6 & $62,636,859.8726 \pm 0.0447$ & -64.7 \\
\hline ZAKYNTHOS & -90.0 & -66.9 & -76.3 & 5.8 & 76.5 & $62,636,860.8691 \pm 0.1161$ & -74.7 \\
\hline KEFALONIA & -82.4 & -41.1 & -63.2 & 9.7 & 63.9 & $62,636,859.1947 \pm 0.0899$ & -57.9 \\
\hline CORFU & -101.7 & -45.7 & -84.6 & 16.7 & 86.1 & $62,636,861.2994 \pm 0.0976$ & -79.0 \\
\hline \multicolumn{8}{|c|}{ GOCOO5s $\left(d / o 170^{+}\right)$} \\
\hline CRETE & -125.2 & -31.7 & -82.1 & 18.0 & 84.0 & $62,636,861.2682 \pm 0.0312$ & -78.7 \\
\hline RHODES & -73.9 & -18.5 & -43.9 & 14.5 & 46.2 & $62,636,857.5066 \pm 0.0669$ & -41.1 \\
\hline SAMOS & -174.3 & -62.6 & -82.7 & 27.9 & 87.0 & $62,636,861.4416 \pm 0.1042$ & -80.4 \\
\hline CHIOS & -69.1 & -21.7 & -39.9 & 12.7 & 41.8 & $62,636,857.9622 \pm 0.0796$ & -45.6 \\
\hline LESVOS & -90.1 & -54.2 & -75.0 & 9.1 & 75.5 & $62,636,861.0694 \pm 0.0624$ & -76.7 \\
\hline LIMNOS & -90.9 & -51.7 & -75.4 & 9.1 & 75.9 & $62,636,860.9246 \pm 0.0919$ & -75.2 \\
\hline THASOS & -67.3 & -47.6 & -56.4 & 6.2 & 56.7 & $62,636,859.0257 \pm 0.1379$ & -56.3 \\
\hline EYVOIA & -103.3 & -37.4 & -69.6 & 11.7 & 70.5 & $62,636,859.7666 \pm 0.0433$ & -63.7 \\
\hline ZAKYNTHOS & -90.0 & -66.9 & -76.2 & 5.8 & 76.4 & $62,636,860.8689 \pm 0.1125$ & -74.7 \\
\hline KEFALONIA & -82.2 & -40.8 & -63.0 & 9.7 & 63.7 & $62,636,859.1679 \pm 0.0872$ & -57.7 \\
\hline CORFU & -101.5 & -45.2 & -84.2 & 16.8 & 85.8 & $62,636,861.2638 \pm 0.0946$ & -78.6 \\
\hline
\end{tabular}


Fig. 6 Zero-level geopotential based on the enhanced DIR-R5 and GOCO05s GGMs for the LVDs of the Greek islands and Turkey. The derived Wo for the Greek LVD is also shown along with IAG conventional value for the WHS

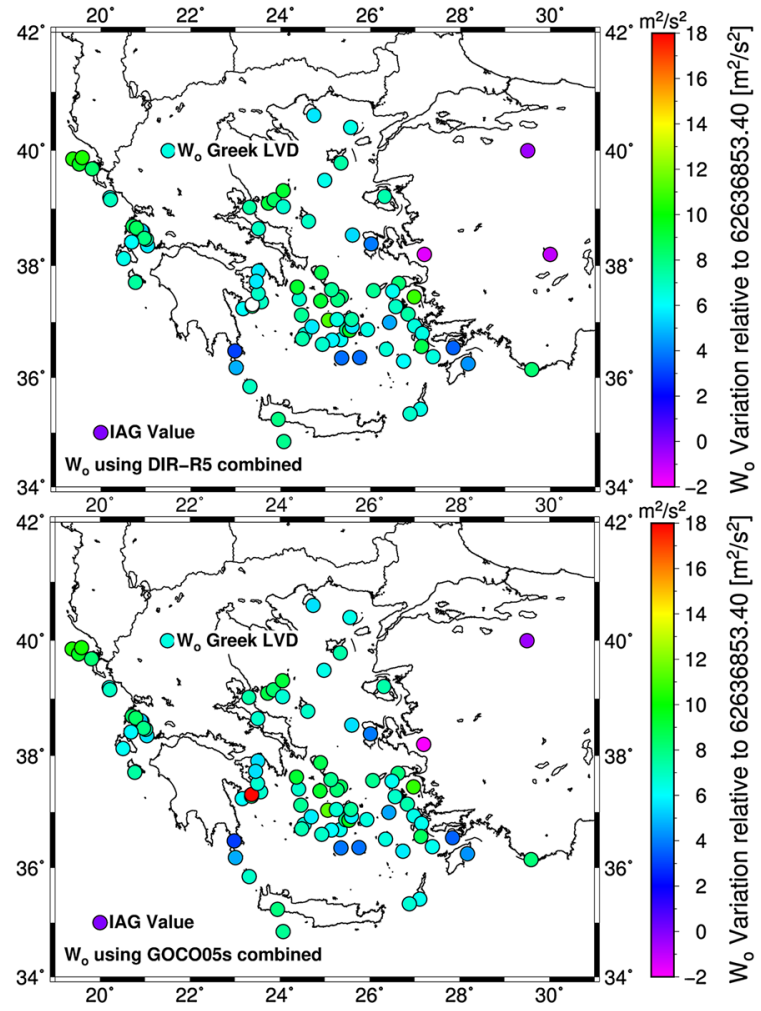

compared to the implied by the IAG $W_{o}$, the situation at the islands varies greatly. Given that the spectrally enhanced GOCO05s has been used as a best estimate for the $\widehat{W}_{o}^{L V D}$ for mainland Greece and that it provides slightly better std for the height residuals over the islands (even though at the mm level therefore statistically insignificant), it is the one selected as the best estimate for the $\widehat{W}_{o}^{L V D}$ of the islands as well (see bottom of Table 5).

\section{2 $\widehat{W}_{o}^{L V D}$ determination in the Turkish sub-regions}

Tables 6 and 7 present the results for the three test areas over Turkey, either using the pure GOCE and the spectrally enhanced GOCE GGMs. Furthermore, they report the potential differences w.r.t. the conventional IAG $W_{o}$ as well as the accuracies achieved in $\widehat{W}_{o}^{L V D}$ determination for the three datasets in Turkey. One immediate conclusion is that even without any spectral enhancement the GOCE GGMs provide results which are very close to those of EGM2008, the latter being evaluated to its $n_{\max }$ of 2190 . For the TUTGA BMs, the GOCE GGMs provide a mean which is just $3 \mathrm{~cm}$ worse than that of EGM2008. For the 31 TUTGA BMs that mean value of the residuals provided by the GOCE GGMs differs between 3.4 and $6 \mathrm{~cm}$. This is due to the high quality of the levelling network in Turkey and its very good inner coherency. The latter can be viewed if one inspects the potential differences between TUTGA 81 and TUTGA 30, which are at the 3-4 cm level, implying that the Turkish leveling network has a uniform bias rather than different ones arising from non-uniform reductions to the data and separate adjustment. After the spectral 
Table 6 Height residuals and $\widehat{W}_{o}^{L V D}$ for Turkey DIR-R5, TIM-R5 and GOCO05s to their $n_{\max }$ [unit: (cm)]

\begin{tabular}{|c|c|c|c|c|c|c|c|}
\hline \multirow[t]{2}{*}{ Model } & \multicolumn{5}{|c|}{$\begin{array}{l}\text { Geoid height residuals } \\
\left(N_{\text {GPS/lev. }}-N_{\text {model }}\right)\end{array}$} & \multicolumn{2}{|c|}{$\begin{array}{l}\text { Gravity potential and offsets relative to } \\
W_{o}=\ldots .53 .4000 \mathrm{~m}^{2} / \mathrm{s}^{2}\end{array}$} \\
\hline & Min & $\operatorname{Max}$ & Mean & Std & Rms & $\widehat{W}_{o}^{L V D}\left(\mathrm{~m}^{2} / \mathrm{s}^{2}\right)$ & $\approx \delta \widehat{W}_{o}^{L V D}(\mathrm{~cm})$ \\
\hline \multicolumn{8}{|l|}{ TUTGA $81 \mathrm{BMs}$} \\
\hline DIR-R5 (d/o 300) & -42.2 & 67.4 & 8.7 & 26.4 & 27.7 & $62,636,852.5519 \pm 0.0256$ & 8.3 \\
\hline TIM-R5(d/o 280) & -50.2 & 67.3 & 8.6 & 27.2 & 28.5 & $62,636,852.5551 \pm 0.0266$ & 8.3 \\
\hline GOCO05s (d/o 280) & -47.5 & 63.4 & 8.7 & 26.2 & 27.6 & $62,636,852.5454 \pm 0.056$ & 8.4 \\
\hline EGM2008 (d/o 2190) & -43.3 & 51.1 & 5.9 & 15.9 & 16.9 & $62,636,852.8248 \pm 0.0155$ & 5.6 \\
\hline \multicolumn{8}{|l|}{ Izmir } \\
\hline DIR-R5 (d/o 300) & -22.7 & 80.3 & 18.0 & 15.4 & 23.7 & $62,636,850.6234 \pm 0.0151$ & 27.2 \\
\hline TIM-R5(d/o 280) & -18.2 & 92.6 & 26.3 & 17.7 & 31.8 & $62,636,850.8170 \pm 0.0174$ & 25.3 \\
\hline GOCO05s (d/o 280) & -20.9 & 91.3 & 23.5 & 18.0 & 29.6 & $62,636,849.5071 \pm 0.0176$ & 38.1 \\
\hline EGM2008 (d/o 2190) & -22.3 & 40.1 & 0.7 & 8.8 & 8.9 & $62,636,852.7454 \pm 0.0086$ & 6.4 \\
\hline \multicolumn{8}{|l|}{ TUTGA $30 \mathrm{BMs}$} \\
\hline DIR-R5 (d/o 300) & -49.3 & 81.9 & 4.1 & 34.6 & 34.8 & $62,636,852.9414 \pm 0.0338$ & 4.6 \\
\hline TIM-R5(d/o 280) & -55.8 & 93.3 & 1.4 & 36.1 & 36.1 & $62,636,853.2056 \pm 0.0353$ & 2.0 \\
\hline GOCO05s (d/o 280) & -55.9 & 87.2 & 1.5 & 36.0 & 36.0 & $62,636,853.1921 \pm 0.0352$ & 2.1 \\
\hline EGM2008 (d/o 2190) & -28.1 & 61.6 & 7.5 & 15.5 & 17.2 & $62,636,852.6056 \pm 0.0153$ & 8.1 \\
\hline
\end{tabular}

enhancement with EGM2008 and the RTM effects, the GOCE-based GGMs outperform EGM2008 by as much as $4 \mathrm{~cm}$, which can be seen mainly in the results referring to the Marmara and Izmir regions. The std of the geoid height residuals obtained when using the enhanced geopotential models to their optimum degrees, d/o of 155 for Marmara and 245 for İzmir, reach the 13 and $7 \mathrm{~cm}$ level, respectively, which is 4 and $1 \mathrm{~cm}$ better than EGM2008. The same conclusion is drawn for the Turkey-wide geoid residuals which are $1 \mathrm{~cm}$ better for the enhanced GOCE models compared to EGM2008.

The BMs over Izmir belong to a Third-order leveling densification network (Bossler 1984), therefore datum/epoch differences may be present since considering the station velocities for such networks is not mandatory. Moreover, the orthometric heights of the Izmir area are determined through a least squares adjustment of leveling observations relying on the TUDKA control network. Consequently, the accuracies of the orthometric heights could be affected both from the distortions of the TUDKA network and improper reductions during leveling. The BM spatial distribution over the area of Izmir is limited, despite presenting a homogeneous and dense GPS/levelling dataset, so that the GGM validation does not provide useful results on the long wavelength behavior of the GOCE models. For sure this behavior of the GOCE GGMs over the network of Izmir and the possible identification of long-wavelength tilts in the GPS/Leveling observations, is worth of investigation in future work. This is so, given that even the spectrally enhanced GOCE GGMs have a mean between 15.6 and $21.5 \mathrm{~cm}$, substantially larger than that of EGM2008, which is almost zero. Given the degree after which EGM2008 is taken into account over Izmir, i.e., 245, it implies that almost all contribution is coming from the GOCE models, especially in the medium wavelengths. Nevertheless, the fact that this bias is maintained after the spectral enhancement with EGM2008, may indicate that part of the geoid signal is 
Table 7 Height residuals and $\widehat{W}_{o}^{L V D}$ for Turkey based on the spectrally enhanced DIR-R5, TIM-R5 and GOCO05s (unit: (cm)]

\begin{tabular}{|c|c|c|c|c|c|c|c|}
\hline \multirow[t]{2}{*}{ Model } & \multicolumn{5}{|c|}{$\begin{array}{l}\text { Geoid height residuals } \\
\left(N_{\text {GPS/lev. }}-N_{\text {model }}\right)\end{array}$} & \multicolumn{2}{|c|}{$\begin{array}{l}\text { Gravity potential and offsets relative to } \\
\boldsymbol{W}_{\boldsymbol{o}}=\ldots .53 .4000 \mathrm{~m}^{2} / \mathrm{s}^{2}\end{array}$} \\
\hline & Min & Max & Mean & Std & Rms & $\widehat{W}_{o}^{L V D}\left(\mathrm{~m}^{2} / \mathrm{s}^{2}\right)$ & $\approx \delta \widehat{W}_{o}^{L V D}(\mathrm{~cm})$ \\
\hline \multicolumn{8}{|l|}{ TUTGA $81 \mathrm{BMs}$} \\
\hline DIR-R5 (d/o 155 $\left.{ }^{+}\right)$ & -36.1 & 31.7 & 4.5 & 12.0 & 12.9 & $62,636,852.9550 \pm 0.0117$ & 4.4 \\
\hline TIM-R5(d/o $\left.155^{+}\right)$ & -36.3 & 31.4 & 4.6 & 12.0 & 12.9 & $62,636,852.9453 \pm 0.0117$ & 4.4 \\
\hline GOCO05s $\left(\mathrm{d} / \mathrm{o} 155^{+}\right)$ & -36.2 & 31.2 & 4.4 & 11.9 & 12.7 & $62,636,852.9664 \pm 0.0116$ & 4.2 \\
\hline EGM2008 (d/o 2190) & -43.3 & 51.1 & 5.9 & 15.9 & 16.9 & $62,636,852.8248 \pm 0.0155$ & 5.6 \\
\hline \multicolumn{8}{|l|}{ Izmir } \\
\hline DIR-R5 (d/o 245 $)$ & -3.1 & 48.8 & 15.6 & 6.9 & 17.1 & $62,636,851.8663 \pm 0.0066$ & 15.0 \\
\hline TIM-R5(d/o $\left.245^{+}\right)$ & 0.7 & 56.8 & 21.5 & 7.3 & 22.7 & $62,636,851.2937 \pm 0.0071$ & 20.6 \\
\hline GOCO05s $\left(\mathrm{d} / \mathrm{o} 245^{+}\right)$ & -0.9 & 55.8 & 19.6 & 7.4 & 21.0 & $62,636,851.4763 \pm 0.0072$ & 18.8 \\
\hline EGM2008 (d/o 2190) & -22.3 & 40.1 & 0.7 & 8.8 & 8.9 & $62,636,852.7454 \pm 0.0086$ & 6.4 \\
\hline \multicolumn{8}{|l|}{ TUTGA $30 \mathrm{BMs}$} \\
\hline DIR-R5 (d/o 245 $)$ & -13.4 & 58.6 & 9.9 & 15.6 & 18.5 & $62,636,852.4287 \pm 0.0153$ & 9.9 \\
\hline TIM-R5(d/o $\left.245^{+}\right)$ & -10.7 & 49.7 & 9.5 & 14.1 & 17.0 & $62,636,852.4716 \pm 0.0138$ & 9.5 \\
\hline GOCO05s (d/o 245 $\left.{ }^{+}\right)$ & -8.8 & 51.9 & 9.7 & 14.2 & 17.2 & $62,636,852.4509 \pm 0.0139$ & 9.6 \\
\hline EGM2008 (d/o 2190) & -28.1 & 61.6 & 7.5 & 15.5 & 17.2 & $62,636,852.6056 \pm 0.0153$ & 8.1 \\
\hline
\end{tabular}

not modelled by EGM2008, due to the data that have been used over the area. Therefore, the conclusion drawn by using GOCE GGMs may be a valid one.

In any case this is a matter of future work and more in depth investigation, since the original levelling traverses and corrections applied need to be examined, in order to identify any possible biases. When the zero-level geopotential values for the Izmir LVD are considered, EGM2008 provides a consistent offset with the IAG $W_{o}$ for all three areas between 5.6 and $8.1 \mathrm{~cm}$. The same holds for the enhanced GOCE-based GGMs, where the shift is between 4.2 and $9.9 \mathrm{~cm}$ for the TUTGA BMs. Although a more detailed investigation including more nationwide BMs over Turkey is needed, a first estimate of the Turkish LVD zero-level geopotential is $\widehat{W}_{o}^{L V D}=62636852.4509 \pm 0.0139 \mathrm{~m}^{2} / \mathrm{s}^{2}$, based on the spectrally enhanced GOCO05s GOCE model.

A final investigation carried out among the 30 TUTGA BMs was to select the ones closer to the Thrace border and to the Aegean coast in order to calculate the local geopotential value and compare them to the ones of the neighboring Greek islands. The considered BMs reside in the Thrace area (BM 1) and the Aegean coast (BM 19, BM 20 and BM 21). From the results achieved it was concluded that BMs 19 and 20 are consistent to each other when the GOCE models are considered. Their potential offsets are between 9 and $14 \mathrm{~cm}$ for all enhanced GOCE GGMs, showing a difference of just 1.2-3.4 cm. BM 21 is very close to the conventional potential of the WHS with an offset between 1.9 and $-3.7 \mathrm{~cm}$. BM1, which is on the European part of Turkey has offsets between -2.6 and -7.1 , so that an offset between the two coasts of Turkey across the Marmara strait between 11 and $22 \mathrm{~cm}$ exists. It is noticed that these results are based on single point estimation, 
therefore they contain a large error. Nevertheless, they are indicative of the possible offset in the Turkish LVD between the European and Asian coasts.

When comparing the potential values for the Turkish BMs with those derived for the Greek islands a significant bias exists, as for instance between Chios and Izmir, being at the $67 \mathrm{~cm}$ level, while it increases to $\sim 1 \mathrm{~m}$ between Lesvos or Limnos and Izmir (BM 20). The same conclusions hold for the northern Aegean, where Samos and BM 1 have an offset of 73-79 $\mathrm{cm}$ for any of the GOCE models used. In any case, these can be considered as preliminary results, since they are based on single-point evaluations for the Turkish coasts, hence they carry a large uncertainty. Nevertheless, they form a first basis of scientific cooperation for the eventual evaluation between of the offset(s) between the Hellenic and Turkish LVDs.

\section{Conclusions}

In this work a detailed evaluation of the latest R5 GOCE GGMs has been presented employing collocated GPS/levelling observations in both Greece and Turkey. Moreover, the zero-level geopotential of mainland Greece and that of 83 of its islands have been determined, given that the latter employ in essence individual LVDs. Finally, a first estimation of the geopotential value for the Turkish LVD has been carried out, acknowledging that the BMs available are very limited. From the results acquired it can be concluded that in both regions the spectrally enhanced GOCE GGMs provide better results than EGM2008, while their combination is very robust showing differences of the order of $0.1-0.6 \mathrm{~cm}$. A significant consistency between the $\widehat{W}_{o}^{L V D}$ estimated by the spectrally enhanced GOCE-based GGMs $\left(<0.02 \mathrm{~m}^{2} / \mathrm{s}^{2}\right.$ or $\left.<0.2 \mathrm{~cm}\right)$ is noticed for all Greek islands studied. The Turkish LVD is very close to the newly adopted global $W_{o}$ by IAG, however, a more detailed investigation including a country wide dataset with higher resolution is necessary. On the other hand, although the Greek mainland LVD is $60 \mathrm{~cm}$ lower compared to that adopted by IAG, the situation at the islands varies greatly, with each island or isle practically realizing its own LVD, which is not connected to that of the zero-level geopotential value at Piraeus harbor. Along the border line significant biases exist, as for instance between Chios and Izmir, being at the $67 \mathrm{~cm}$ level and almost a meter between Izmir and Samos.

Acknowledgements The part of this work referring to the zero-level geopotential estimation for mainland Greece and the Greek islands has been funded by the European Space Agency in the frame of the PRODEX funded $\mathrm{GOCE}^{+++}$project (CN4000106380C3). The GPS/levelling BMs over Greece are available within a dedicated memorandum between Ktimatologio S.A. and the School of Rural and Surveying Engineering. The TUTGA BMs over Turkey are available with funds by TUBITAK Research Project with contract number 114Y581 and IzJRS network BMs are provided by ITU Geodesy Division. All plots were generated using the Generic Mapping Tools v5.3.1 software (Wessel et al. 2013). All spherical harmonic datasets for the GOCE and GOCE/GRACE GGMs have been accessed through the ICGEM (Barthelmes and Köhler 2016) service of IGFS. The constructive remarks by two anonymous reviewers are gratefully acknowledged, since they evidently improved the initial version of the paper.

\section{References}

Ayan T et al (2001) Izmir Geodetic Reference System-2001 (IzJRS-2001). Technical Report, No. ITU 2000/2294, Istanbul Technical University, Geodesy Division, Istanbul, Turkey 
Ayhan ME et al (2002) Turkish National Fundamental GPS network-1999 report, Map Journal Special Edition, 16, Ankara, Turkey

Albertella A, Savcenko R, Janjić T, Rummel R, Bosch W, Schröter J (2012) High resolution dynamic ocean topography in the Southern Ocean from GOCE. Geophys J Int 190(2):922-930. doi:10.1111/j.1365246X.2012.05531.x

Andritsanos VD, Arabatzi O, Gianniou M, Pagounis V, Tziavos IN, Vergos GS, Zacharis E (2015) Comparison of various GPS processing solutions toward an efficient validation of the Hellenic vertical network: the ELEVATION project. J Surv Eng. doi:10.1061/(ASCE)SU.1943-5428. 0000164,04015007

Ayhan ME, Demir C (1993) Turkey National Vertical Control Network (TUDKA) and its improvement. In: Proceedings of Turkish National Association of Geodesy and Geophysics (TUJJB) General Assembly, pp 547-562

Bamler R (1999) The SRTM mission: a world-wide 30 m resolution DEM from SAR interferometry in 11 days. In: Fritsch D, Spiller R (eds) Photogrammetric week 99. Wichmann Verlag, Heidelberg, pp 145-154

Barthelmes F, Köhler W (2016) International Centre for Global Earth Models (ICGEM). In: Drewes H, Kuglitsch F, Adám J et al. (eds) The geodesists handbook 2016. J Geod 90(10): 907-1205. doi:10. 1007/s00190-016-0948-z

Bingham RJ, Knudsen P, Andersen OB, Pail R (2011) An initial estimate of the North Atlantic steady-state geostrophic circulation from GOCE. Geophys Res Lett 38(1):L01606. doi:10.1029/2010GL045633

Bossler JD (1984) Standards and specifications for geodetic control networks. Federal Geodetic Control Committee, Rockville

Brockmann JM, Zehentner N, Höck E, Pail R, Loth I, Mayer-Gürr T, Schuh W-D (2014) EGM_TIM_RL05: an independent geoid with centimeter accuracy purely based on the GOCE mission. Geophys Res Lett 41(22):8089-8099. doi:10.1002/2014GL061904

Bruinsma S, Foerste C, Abrikosov O, Marty J-C, Rio M-H, Mulet S, Bonvalot S (2013) The new ESA satellite-only gravity field model via the direct approach. Geophys Res Lett 40(14):3607-3612. doi:10. $1002 / \mathrm{grl} .50716$

Burša M, Kouba J, Müller A, Raděj K, True SA, Vatrt V, Vojtísková M (2001) Determination of geopotential differences between local vertical datums and realization of a world height system. Stud Geophys Geod 45:127-132

Carrion D, Vergos GS, Albertella A, Barzaghi R, Tziavos IN, Grigoriadis VN (2015) Assessing the GOCE models accuracy in the Mediterranean area. Newton's Bull 5:63-82

Ekman M (1989) Impacts of geodynamic phenomena on systems for heights and gravity. Bull Géod 63:281-296

Filmer MS, Featherstone WE, Kuhn M (2010) The effect of EGM2008-based normal, normal-orthometric and Helmert orthometric height systems on the Australian levelling network. J Geodesy 8(8):501-513. doi:10.1007/s00190-010-0388-0

Forsberg R, Tscherning CC (2008) An overview manual for the GRAVSOFT geodetic gravity field modelling programs, 2nd ed, DTU-Space

Grigoriadis VN, Kotsakis C, Tziavos IN, Vergos GS (2014) Estimation of the geopotential value Wo for the local vertical datum of continental Greece using EGM08 and GPS/levelling data. In: Marti U (ed) Gravity, geoid and height systems, IAG symposia, vol 141. Springer, Berlin, pp 249-255. doi:10.1007/ 978-3-319-10837-7_32

Gruber T, Rummel R (2014) GOCE gravity field models-overview and performance analysis. In: 5th international GOCE user workshop, Paris

Gruber Th, Visser PNAM, Ackermann Ch, Hosse M (2011) Validation of GOCE gravity field models by means of orbit residuals and geoid comparisons. J Geod 85(11):845-860. doi:10.1007/s00190-0110486-7

Gruber T, Gerlach C, Haagmans R (2012) Intercontinental height datum connection with GOCE and GPSlevelling data. J Geod Sci 2(4):270-280. doi:10.2478/v10156-012-0001-y

Heck B, Rummel R (1990) Strategies for solving the vertical datum problem using terrestrial and satellite geodetic data. In: Sünkel H, Baker T (eds) Sea surface topography and the geoid, IAG symposia, vol 104 Springer, Berlin, pp 116-128. doi:10.1007/978-1-4684-7098-7_14

Heiskanen WA, Moritz H (1967) Physical geodesy, WH Freeman and Co., San Francisco (reprinted by TU Graz)

Hirt C, Gruber T, Featherstone WE (2011) Evaluation of the first GOCE static gravity field models using terrestrial gravity, vertical deflections and EGM2008 quasigeoid heights. J Geod 85(10):723-740. doi:10.1007/s00190-011-0482-y

Kaula WM (1966) Theory of satellite geodesy. Dover, New York 
Knudsen P, Bingham R, Andersen OB, Rio M-H (2011) A global mean dynamic topography and ocean circulation estimation using a preliminary GOCE gravity model. J Geod 85(11):861-879. doi:10.1007/ s00190-011-0485-8

Kotsakis C, Katsambalos K (2010) Quality analysis of global geopotential models at 1542 GPS/levelling benchmarks over the Hellenic mainland. Surv Rev 42(318):327-344

Kotsakis C, Katsambalos K, Ampatzidis D (2012) Estimation of the zero-height geopotential level $W_{o}^{L V D}$ in a local vertical datum from inversion of co-located GPS, leveling and geoid heights: a case study in the Hellenic islands. J Geod 86(6): 423-439. doi:10.1007/s00190-011-0530-7

Mayer-Gürr T, Pail R, Gruber T, Fecher T, Rexer M, Schuh W-D, Kusche J, Brockmann J-M, Rieser D, Zehentner N, Kvas A, Klinger B, Baur O, Höck E, Krauss S, Jäggi A (2015) The combined satellite gravity field model GOCO05s, Vienna, Austria

Moritz H (2000) Geodetic reference system 1980. J Geod 74(1):128-133. doi:10.1007/s001900050278

Niiler PP, Maximenko NA, McWilliams JC (2003) Dynamically balanced absolute sea level of the global ocean derived from near-surface velocity observations. Geophys Res Lett 30(22):2164. doi:10.1029/ 2003GL018628

Pavlis N, Holmes S, Kenyon S, Factor J (2012) The development and evaluation of the Earth Gravitational Model 2008 (EGM2008). J Geophys Res 117:B04406. doi:10.1029/2011JB008916

Petit G, B Luzum (eds) (2010) IERS conventions 2010. IERS Technical Note 36: Verlag des Bundesamts für Kartographie und Geodäsie, Frankfurt a. M. ISBN 3-89888-989-6

Rapp RH, Nerem RS, Shum CK, Klosko SM, Williamson RG (1991) Consideration of permanent tidal deformation in the orbit determination and data analysis for the topex/poseidon mission. NASA TM 100775, Goddard Space Flight Center, Greenbelt, MD

Rio M-H, Hernandez F (2004) A mean dynamic topography computed over the world ocean from altimetry, in situ measurements and a geoid model. J Geophys Res 109:C12032. doi:10.1029/2003JC002226

Sánchez L, Cunderlik L, Dayoub N, Mikula K, Minarechova Z, Sima Z, Vatrt V, Vojtiskova M (2016) A conventional value for the geoid reference potential Wo. J Geod 90(9):815-835. doi:10.1007/s00190016-0913-x

Šprlák M, Gerlach C, Pettersen PR (2012) Validation of GOCE global gravity field models using terrestrial gravity data in Norway. J Geod Sci 2(2):134-143. doi:10.2478/v10156-011-0030-y

Takos I (1989) New adjustment of the national geodetic networks in Greece (in Greek). Bull Hell Mil Geogr Serv 49(136):19-93

Tscherning CC, Rapp RH (1974) Closed covariance expressions for gravity anomalies, geoid undulations, and deflections of the vertical implied by anomaly degree-variance models. The Ohio State University, Reports of the Department of Geodetic Science, Report 208, Columbus, OH

Tziavos IN, Vergos GS, Grigoriadis VN (2010) Investigation of topographic reductions and aliasing effects to gravity and the geoid over Greece based on various digital terrain models. Surv Geophys 31(3):23-67. doi:10.1007/s10712-009-9085-z

Tziavos IN, Vergos GS, Grigoriadis VN, Andritsanos VD (2012) Adjustment of collocated GPS, geoid and orthometric height observations in Greece. Geoid or orthometric height improvement? In: Kenyon S, Pacino M-C, Marti U (eds) Geodesy for planet Earth, IAG symposia, vol 136. Springer, Berlin, pp 481-488. doi:10.1007/978-3-642-20338-1_58

Tziavos IN, Vergos GS, Mertikas SP, Daskalakis A, Grigoriadis VN, Tripolitsiotis A (2013) The contribution of local gravimetric geoid models to the calibration of satellite altimetry data and an outlook of the latest GOCE GGM performance in GAVDOS. Adv Space Res 51(8):1502-1522. doi:10.1016/j.asr. 2012.06.013

Tziavos IN, Vergos GS, Grigoriadis VN, Tzanou EA, Natsiopoulos DA (2016) Validation of GOCE/ GRACE satellite only and combined global geopotential models over Greece, in the frame of the GOCESeaComb Project. In: Rizos C, Willis P (eds) IAG 150 years, IAG symposia, vol 143. Springer, Berlin, pp 297-304. doi:10.1007/1345_2015_160

Vergos G, Grigoriadis V, Tziavos I, Kotsakis C (2014) Evaluation of GOCE/GRACE Global Geopotential Models over Greece with collocated GPS/levelling observations and local gravity data. In: Marti U (ed) Gravity, geoid and height systems, IAG symposia, vol 141. Springer, Berlin, pp 85-92. doi:10.1007/ 978-3-319-10837-7_11

Vergos GS, Andritsanos VD, Grigoriadis VN, Pagounis V, Tziavos IN (2015) Evaluation of GOCE/GRACE GGMs over Attika and Thessaloniki, Greece, and Wo determination for height system unification. IAG symposia, vol 145, Springer, New York. doi:10.1007/1345_2015_53

Wessel P, Smith WHF, Scharroo R, Luis JF, Wobbe F (2013) Generic mapping tools: improved version released. EOS Trans AGU 94:409-410 